\title{
Utilization profile of enoxaparin in hospitalized patients with Chronic Kidney Disease in southern Brazil
}

\author{
Carolina Araujo Cirne ${ }^{\circledR 1}$, Tatiane Araujo Castro Machado²
}

\begin{abstract}
${ }^{1}$ São Lucas University Hospital, Pontifícia Universidade Católica do Rio Grande do Sul, Clinical Pharmacy Department, Porto Alegre, RS, Brazil, ${ }^{2}$ School of Pharmacy, Pontificia Universidade Católica do Rio Grande do Sul, Porto Alegre, RS, Brazil
\end{abstract}

\begin{abstract}
Chronic Kidney Disease (CKD) patients usually require the use of anticoagulants for treatment or prevention of thromboembolic diseases. One such commonly used anticoagulant is enoxaparin. However, special attention is advised when using this drug for CKD patients because dosage adjustments may be needed. This prospective observational study was conducted in adult patients ( $>18$ years) with CKD stages 3 to 5 who were followed-up daily via prescriptions, medical records and laboratory tests. Enoxaparin doses, renal function and adverse drug events (ADEs) were thus monitored. Of the 87 ADEs identified in this study, 56 (64.3\%) occurred in patients requiring enoxaparin prescription adjustment. Out of the 9 patients who had severe ADEs, $8(88.9 \%)$ needed enoxaparin prescription adjustment. The results of this study suggest an overall increased risk of major bleeding and ADEs in patients requiring enoxaparin prescription adjustment. Further investigation of alternative dosing regimens in patients with CKD to maintain efficacy while reducing risks is imperative, as are studies on the utility of monitoring anti-factor Xa activity to guide dosing of enoxaparin. In addition, the role of clinical pharmacists in the management of CKD patients is crucial, as dose adjustments are often necessary.
\end{abstract}

Keywords: Low molecular weight heparin. Enoxaparin. Renal disease. Anticoagulation management. Therapeutic drug monitoring. Clinical pharmacists.

\section{INTRODUCTION}

Chronic Kidney Disease (CKD) is a global public health problem that affects more than 20 million people in the US (Coresh et al., 2007). The disease is characterized by a progressive decrease in kidney function, leading to related complications such as increased risk of cardiovascular disease. In fact, the mortality of patients with CKD is strongly related to their elevated incidence of cardiovascular disease (Levey et al., 2007). In addition, CKD is typically associated with dysfunction in the homeostatic pathway. During less advanced stages of the disease, a prothrombotic tendency can be observed. In more severe stages, patients suffer from a prothrombotic tendency associated with bleeding, because uremicrelated toxin exposure damages platelets in these patients (Jalal, Chonchol, Targher, 2010). Furthermore, patients with CKD are at increased risk for adverse drug events (ADE) due to several reasons, including reduced ability to

\footnotetext{
*Correspondence: C. A. Cirne. Clinical Pharmacy, São Lucas University Hospital, PUCRS. Av. Ipiranga, n 6690, 90160-090 Porto Alegre, RS, Brazil. E-mail: carolcirne@gmail.com
}

eliminate drugs through the renal pathway (Yeung et al., 2014).

Anticoagulation therapy is frequently required for CKD patients, because of their greater risk of thromboembolic events (Jalal, Chonchol, Targher, 2010; Dager, Kiser, 2010). Previous studies have demonstrated the better efficacy and safety of enoxaparin when compared to unfractionated heparin for the prevention of venous thromboembolism (Sherman et al., 2007). Low molecular weight heparins (LMWHs), such as enoxaparin, have lower molecular weight and reduced binding to proteins and cells. LMWHs have lower anti-IIa activity relative to anti-Xa activity and a more predictable anticoagulant response, eliminating the need for routine laboratory monitoring (Sharif-Askari et al., 2014). However, the use of enoxaparin in CKD patients may be unfavorable, because of its clearance via renal mechanisms and consequent accumulation of the drug's anticoagulant effect (Brophy, Wazny, Gehr, 2001; Verbeeck, Musuamba, 2009). Therefore, special attention is advised when using this drug for CKD patients, as dosage adjustment may be needed in cases with severe $\mathrm{CKD}$, defined as creatinine 
clearance $<30 \mathrm{~mL} / \mathrm{min} / 1.73 \mathrm{~m}^{2}$ (British National Formulary, 2012; Shaikh, Regal, 2017).

Additionally, caution is also required when using enoxaparin in other specific populations. These groups include geriatric patients ( $>75$ years old) and lowweight patients (women $<45 \mathrm{~kg}$ and men $<57 \mathrm{~kg}$ ). All such patients should be observed carefully for signs and symptoms of bleeding. On the other hand, obese patients $\left(\mathrm{BMI}>30 \mathrm{~kg} / \mathrm{m}^{2}\right)$ are at higher risk of thromboembolism, although there is no consensus for dose adjustment in these cases (Sanderink et al., 2002b).

The most common adverse effect of enoxaparin is bleeding, as with all anticoagulants. Moreover, ecchymosis, hematoma, thrombocytopenia, hematuria and anemia may occur when this drug is administered (UpToDate, 2018; Micromedex, 2018). Additionally, concurrent use of enoxaparin and drugs such as other anticoagulants (e.g. heparin and warfarin), antiplatelets (e.g. clopidogrel), nonsteroidal anti-inflammatory drugs (e.g. metamizole), selective serotonin reuptake inhibitors (SSRIs) (e.g. fluoxetine) and selective serotoninnorepinephrine reuptake inhibitors (SNRIs) (e.g. venlafaxine) may result in an increased risk of bleeding (Micromedex, 2018). Nevertheless, at the recommended doses, single injections of enoxaparin do not significantly influence platelet aggregation or affect global clotting time and International Normalized Ratio (INR) (UpToDate, 2018; Micromedex, 2018).

Due to the relevance of this issue, the present prospective observational study sought to examine whether the use of unadjusted doses of enoxaparin for the prevention and treatment of thrombotic events in hospitalized patients with CKD was associated with adverse outcomes. The authors also analyzed whether doses of enoxaparin were correctly prescribed for specific populations reported in the literature (patients with GFR $<30 \mathrm{~mL} / \mathrm{min} / 1.73 \mathrm{~m}^{2}$, elderly, obese and low-weight patients), and drug interactions related to adverse events.

\section{MATERIAL AND METHODS}

\section{Study design}

This prospective observational study was conducted at a 620-bed university hospital located in southern Brazil. The present study is part of a broader project whose main objective is to verify the role of clinical pharmacists in the treatment of CKD patients. Therefore, the sample used in this study is only part of a larger data bank used for several other analyses. This project was approved by the Ethics Committee (number: 6009 and 1.064.843) of São Lucas
University Hospital. The sample consisted of patients admitted to two internal adult medicine wards ( 140 beds).

\section{Patients and data collection}

Adult patients (age $>18$ years) admitted between December 2014 and November 2015 with CKD stages 3 to 5 (estimated glomerular filtration rate [eGFR] $10-50 \mathrm{~mL} / \mathrm{min} / 1.73 \mathrm{~m}^{2}$ ) not receiving dialysis were included. The estimated GFR calculation was standardized for use in the MDRD (Modification of Diet in Renal Disease) Study equation. It is recommended by several authors (Verbeech, Musuamba, 2009; Via-Sosa, Lopes, March, 2013; Arrabal-Duran et al., 2014), for it yields a high estimate of GFR as it takes into account the serum creatinine, age, sex and ethnicity of the patient:

GFR $\left(\mathrm{mL} / \mathrm{min} / 1.73 \mathrm{~m}^{2}\right)=186 \times($ serum creatinine $)-$ $1.154 \times$ (age) $-0.203 \times(0.742$ if female $) \times(1.21$, if AfroAmerican).

For calculation purposes, the ethnic background declared by the patient at the time of hospital admission and registered on the computer system was used.

The CKD classification used in this study was determined based on the National Kidney Foundation Kidney Disease Outcomes Quality Initiative (NKF KDOQI) which classifies CKD into five stages. The definition of stages 1 and 2 CKD is based upon manifestations of renal damage, i.e., presence of either micro- or macro-albuminuria, hematuria, or abnormalities on renal ultrasound. However, patients at these stages are generally asymptomatic and determination of the eGFR during these earlier stages is required only to distinguish between stages 1 and 2 (eGFR $>90$ or $60-89 \mathrm{~mL} / \mathrm{min} / 1.73 \mathrm{~m}^{-2}$, respectively). At more advanced stages ( 3 and $4 \mathrm{CKD}$ ), kidney function begins to deteriorate. Eventually, kidney failure (stage 5 CKD) ensues, and renal replacement therapy is required. Stages 3,4 , and 5 are defined exclusively by GFR (eGFR 30-59, $15-29$ or $<15 \mathrm{~mL} / \mathrm{min} / 1.73 \mathrm{~m}^{-2}$, respectively) (de Jong, Gansevoort, 2008; Verbeech, Musuamba, 2009).

For each patient that met the study inclusion criteria, data was collected with the aid of the pharmacy service computerized report issued on Mondays, Wednesdays and Fridays. Data collected encompassed demographic characteristics, including age, ethnicity and sex; physical examination results, including weight; length of hospital stay, length of patient follow-up, clinical history, reason for admission, comorbidities, allergies, enoxaparin doses prescribed, laboratory tests and ADEs. A list of predictable 
ADEs was also compiled with information extracted from the Medscape, Micromedex and Drug Prescribing in Renal Failure (Aronoff et al., 2007; MedScape, 2018; Micromedex, 2018; UpToDate, 2018) databases.

Patients with advanced CKD on peritoneal dialysis or hemodialysis were excluded from the study due to the fact that dialysis may replace the kidney in the process of elimination of many drugs, thus no dose adjustment would be necessary. Patients hospitalized for less than five days were also excluded because in these cases there would not be sufficient time for ADE monitoring.

Patients were followed up daily via prescriptions, medical records and laboratory tests, until change of unit, hospital discharge or death. Enoxaparin doses, renal function and adverse events were thus monitored.

\section{Identification of ADEs}

The identification of possible ADEs was performed based on close monitoring of medical records and laboratory test results by clinical pharmacists. Important changes in laboratory results or vital signs were considered injuries and symptoms, as well as changes in medical records. The researchers were previously trained in collecting information from medical records and identifying adverse events.

The ADEs were classified according to severity as mild, those of short duration (1-2 days) in which there was no need to stop the treatment and that did not prolong length of hospital stay; moderate, those requiring change in treatment, without suspension of the medication, prolonging hospitalization or otherwise and requiring specific treatment; major, those considered to be life-threatening, resulting in the need for specific treatment, which may increase hospitalization time; or lethal, those that contributed to the patient's death (World Health Organization, 2012).

\section{Statistical analysis}

The Statistical Package for the Social Sciences version 24.0 (SPSS Inc., Chicago, IL) was used for statistical analysis. Continuous variables were expressed as means and discrete variables as quantities and percentages.

\section{RESULTS AND DISCUSSION}

\section{Results}

\section{Population}

Seventy patients prescribed enoxaparin with GFR $\leq 50 \mathrm{~mL} / \mathrm{min} / 1.73 \mathrm{~m}^{2}$ were followed up. This follow-up occurred daily, using the computerized medical records, until hospital discharge, transfer to another hospitalization unit or death. Patients whose hospitalization time was less than 5 days were excluded from the study.

The mean length of hospital stay was 19.7 days $( \pm 15.1)$ and follow-up time was 12.3 days $( \pm 8.1)$. The majority of patients were men $(n=39 ; 55.7 \%)$, with a mean age of 65.7 years $( \pm 12.5)$ and weight of $74.0 \mathrm{~kg}$ $( \pm 15.2)$. Stage CKD 3 was the most frequent $(84.3 \%)$ and $88.6 \%$ of the patients were not Afro-American. The main reason for hospitalization was unstable angina (17.1\%), followed by stroke (15.7\%) and congestive heart failure $(14.3 \%)$. Patient characteristics are presented in Table I.

TABLE I - CKD patient characteristics

\begin{tabular}{lc}
\hline Characteristics & $(\mathrm{n}=70)$ \\
\hline Age (years) & \\
$\quad$ Mean (SD) & $65.7( \pm 12.5)$ \\
$\quad$ Median & $68(31-85)$ \\
Sex (\%) & \\
$\quad$ Male & $39(55.7)$ \\
$\quad$ Female & $31(44.3)$ \\
Ethnicity (\%) & \\
$\quad$ All other races & $62(88.6)$ \\
$\quad$ Afro-American & $8(11.4)$ \\
Weight (kg) & \\
$\quad$ Mean (SD) & $74.0( \pm 15.2)$ \\
$\quad$ Median & $74(46-118)$ \\
Length of hospital stay (days) & \\
$\quad$ Mean (SD) & $19.7( \pm 15.1)$ \\
$\quad$ Median & $15(5-99)$ \\
Length of patient follow-up (days) & \\
$\quad$ Mean (SD) & $12.3( \pm 8.1)$ \\
$\quad$ Median & $11(5-37)$ \\
CKD Stage (\%) & \\
3 & $59(84.3)$ \\
4 & $10(14.3)$ \\
5 & $1(1.4)$ \\
ICD on admission (\%) & \\
Unstable angina & $12(17.1)$ \\
Stroke, not specified & $11(15.7)$ \\
Congestive heart failure & $10(14.3)$ \\
Sepsis, unspecified & $6(8.6)$ \\
AMI, unspecified & $2(2.9)$ \\
Embolism and thrombosis of arteries \\
of the lower extremities & $2(2.9)$ \\
Others & \\
\hline Abtreviation & $27(38.6)$ \\
\hline
\end{tabular}
Abbreviations: ICD, International Statistical Classification of Diseases and Related Health Problems; AMI, Acute myocardial infarction. 


\section{Enoxaparin Prescriptions}

Nine hundred and ninety-four drugs were prescribed, with an average of 14.2 medications per patient $( \pm 3.7)$. The main indication for enoxaparin prescription was deep vein thrombosis (DVT) treatment (45.7\%), followed by DVT prophylaxis $(28.6 \%)$ and acute coronary syndromes (25.7\%). Therefore, the most commonly prescribed enoxaparin dose was $60 \mathrm{mg}$ BID (32.9\%), followed by $40 \mathrm{mg}$ QD (27.1\%). Of these cases, enoxaparin was adequately prescribed in $44(62.9 \%)$ patients, whilst dosage adjustments were required for $26(37.1 \%)$ patients. The most frequent type of adjustment observed was dose reduction (17.1\%), followed by change in both dose and frequency of administration (15.7\%), increase in administration frequency (2.9\%) and dose increase (1.4\%) (Table II).

Enoxaparin was appropriately prescribed in 37 (52.9\%) patients with GFR 50-30 mL/min/1.73 $\mathrm{m}^{2}$, when dose adjustment based on renal function is not yet recommended. Of the $20(35.1 \%)$ patients with GFR $50-30 \mathrm{~mL} / \mathrm{min} / 1.73 \mathrm{~m}^{2}$ requiring prescription adjustment, 15 (26.3\%) presented ADE. Regarding the specific populations described in the literature (Aronoff et al., 2007; Rondina et al., 2010; Product information: Lovenox ${ }^{\circledR}, 2017$; Micromedex, 2018; UpToDate, 2018), dosage adjustment should occur in patients with GFR $<30 \mathrm{~mL} / \mathrm{min} / 1.73 \mathrm{~m}^{2}$, since under these conditions exposure to the drug is significantly increased. Inadequate doses of enoxaparin were prescribed to 6 (46.2\%) of the patients with GFR $<30 \mathrm{~mL} / \mathrm{min} / 1.73 \mathrm{~m}^{2}$. Despite accurate prescription, $9(69.2 \%)$ patients with GFR $<30 \mathrm{~mL} / \mathrm{min} / 1.73 \mathrm{~m}^{2}$ had ADE. Of the 18 (25.7\%) elderly patients in this study (mean age 79.5 years, maximum age 85 years), 7 (38.9\%) needed dose adjustment and $11(61.1 \%)$ had ADE; similarly, among the 19 (27.1\%) obese patients (mean BMI $33.9 \mathrm{~kg} / \mathrm{m}^{2}$, maximum BMI $\left.45.7 \mathrm{~kg} / \mathrm{m}^{2}\right)$ only $7(36.8 \%)$ required prescription adjustment and 13 (68.4\%) experienced ADE, confirming that special attention for these groups is indeed required. All obese patients who had bleeding as an $\mathrm{ADE}$ $(\mathrm{n}=4)$ required prescription adjustment, and represented $50 \%$ of the patients that presented bleeding in this study. Finally, of the $3(4.3 \%)$ low-weight patients (mean weight $53 \mathrm{~kg}$, minimum weight $51 \mathrm{~kg}$ ) in this study, $2(66.7 \%)$ requested adjustment and had $\mathrm{ADE}$.

\section{ADES}

Of the 70 patients involved in the study, 43 (61.4\%) had at least one ADE. A total of 87 ADEs were identified (mean $2.02 \pm 1.63$, median 2, 1-10). ADEs classified as moderate intensity were most frequent $(n=47,54 \%)$, followed by severe $(n=23,26.4 \%)$ and mild $(n=17$,
TABLE II - Prescription characteristics

\begin{tabular}{lc}
\hline Characteristics & $(\mathrm{n}=70)$ \\
\hline Medications per patient & $14.2( \pm 3.7)$ \\
$\quad$ Mean (SD) & $14(7-23)$ \\
$\quad$ Median & \\
Enoxaparin indication & $32(45,7)$ \\
$\quad$ DVT treatment & $20(28.6)$ \\
$\quad$ DVT prophylaxis & $18(25.7)$ \\
$\quad$ Acute coronary syndromes (UA, & \\
NSTEMI and STEMI) & \\
Enoxaparin doses prescribed (\%) & $19(27.1)$ \\
40 mg QD & $7(10.0)$ \\
60 mg QD & $4(5.7)$ \\
40 mg BID & $23(32.9)$ \\
60 mg BID & $9(12.9)$ \\
80 mg BID & $8(11.4)$ \\
Others & \\
Types of adjustment required (\%) & $44(62.9)$ \\
None & $12(17.1)$ \\
Dose reduction & $2(2.9)$ \\
Increase in administration frequency & $11(15.7)$ \\
Change in dose and administration & \\
frequency & $1(1.4)$ \\
Dose increase & \\
\hline
\end{tabular}

Abbreviations: DVT, Deep vein thrombosis; UA, Unstable angina; NSTEMI, non-ST-elevation myocardial infarction; STEMI, ST-elevation myocardial infarction.

TABLE III - Prescriptions for specific populations

\begin{tabular}{lccc}
\hline & N (\%) & $\begin{array}{c}\text { N Adjustment } \\
(\%)\end{array}$ & $\begin{array}{c}\text { ADE } \\
(\%)\end{array}$ \\
\hline $\begin{array}{l}\text { GFR } \\
50-30 \mathrm{~mL} / \mathrm{min} / 1.73 \mathrm{~m}^{2}\end{array}$ & $57(52.9)$ & $20(35.1)$ & $15(26.3)$ \\
\hline $\begin{array}{l}\mathrm{GFR} \\
<30 \mathrm{~mL} / \mathrm{min} / 1.73 \mathrm{~m}^{2}\end{array}$ & $13(18.6)$ & $6(46.2)$ & $9(69.2)$ \\
\hline $\begin{array}{l}\text { Elderly } \\
\text { (age }>75 \text { years })\end{array}$ & $18(25.7)$ & $7(38.9)$ & $11(61.1)$ \\
\hline $\begin{array}{l}\text { Obese } \\
\left(\text { BMI }>30 \mathrm{~kg} / \mathrm{m}^{2}\right)\end{array}$ & $19(27.1)$ & $7(36.8)$ & $13(68.4)$ \\
\hline $\begin{array}{l}\text { Low-weight } \\
(\text { women }<45 \mathrm{~kg} \text { and } \\
\text { men }<57 \mathrm{~kg})\end{array}$ & $3(4.3)$ & $2(66.7)$ & $2(66.7)$ \\
\hline
\end{tabular}

$19.5 \%)$. No lethal reactions were observed. Figure 1 summarizes the ADEs analyzed in this study. 


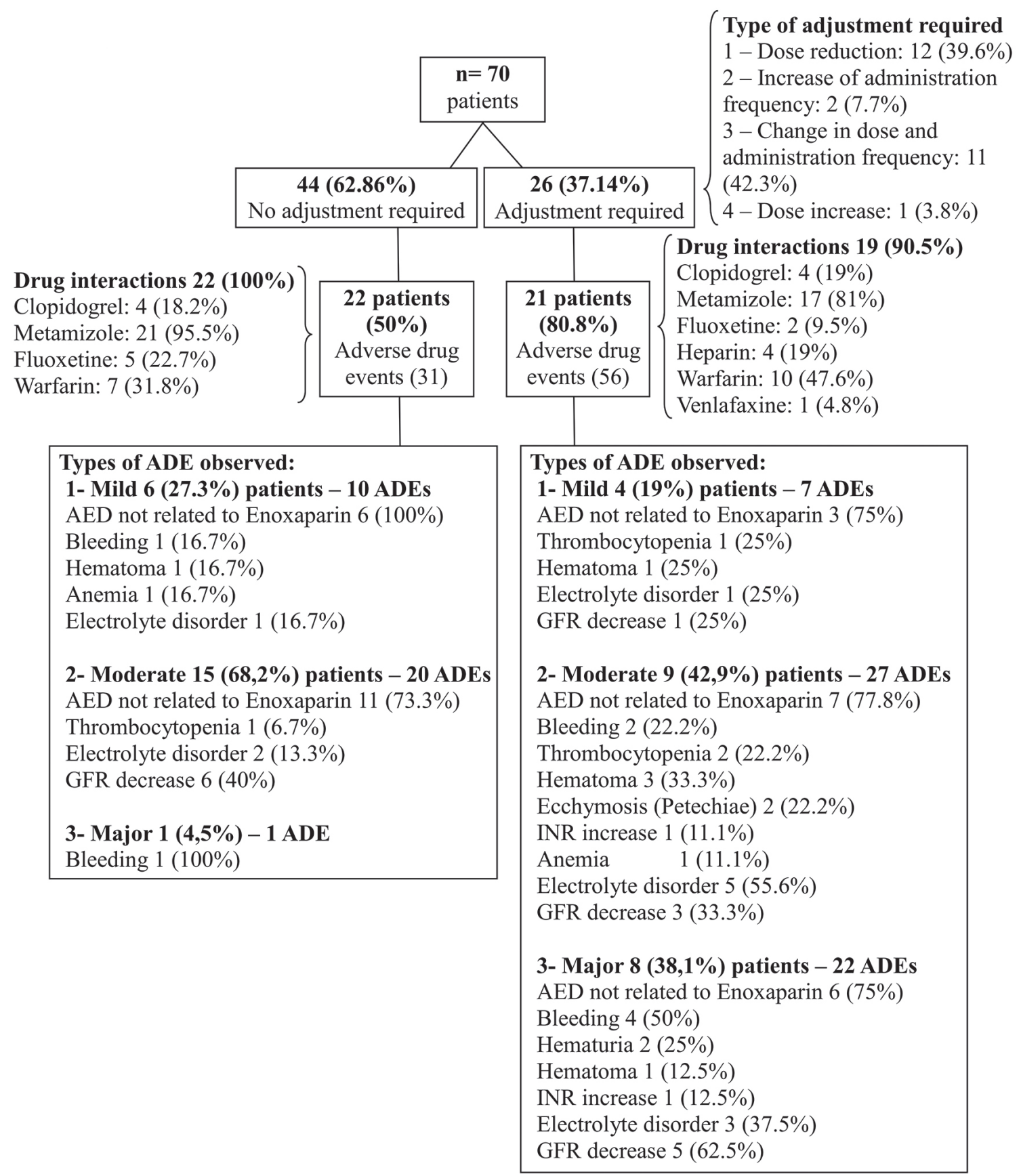

FIGURE 1 - Summary of ADEs analyzed.

The most frequent ADEs were reactions not related to enoxaparin (37.9\%), followed by worsening of renal function (significant reduction in GFR) $(18.4 \%)$ and electrolyte disturbances (hyperkalemia, hypokalemia, uremia) (12.6\%). Additionally, predictable ADEs related to enoxaparin described in the literature occurred, such as bleeding $(9.2 \%)$, hematuria $(5.7 \%)$, hematoma $(4.6 \%)$, thrombocytopenia (4.6\%), ecchymosis (petechiae) $(2.3 \%)$, INR increase $(2.3 \%)$ and anemia (2.3\%). Regarding the GFR, INR and platelet counts, laboratory results at the beginning and end of patient follow-up were evaluated. These values are presented in Table IV.

It was observed that $25(96.1 \%)$ patients who needed dose decrease adjustment in enoxaparin prescription had a mean $36.5 \%$ INR increase, whilst patients with accurate enoxaparin dosage $(\mathrm{n}=38)$ had almost half this INR increase (mean 16.6\%). In addition, of the 87 ADEs identified in this study, $56(64.3 \%)$ occurred in those patients who required enoxaparin prescription adjustment. Out of the nine patients who presented severe intensity 
TABLE IV - Laboratory test results

\begin{tabular}{|c|c|c|c|}
\hline \multicolumn{3}{|l|}{ Results } & \multirow[t]{2}{*}{$(\mathrm{n}=70)$} \\
\hline \multicolumn{2}{|c|}{ Initial GFR $\left(\mathrm{mL} / \mathrm{min} / 1.73 \mathrm{~m}^{2}\right)$} & Final GFR (mL/min/1.73m²) & \\
\hline Mean (SD) & $39.26( \pm 8.7)$ & Mean (SD) & $46.00( \pm 12.6)$ \\
\hline Median & $41.00(10-50)$ & Median & $47.50(13-71)$ \\
\hline \multicolumn{2}{|l|}{ Initial INR } & \multicolumn{2}{|l|}{ Final INR } \\
\hline Mean (SD) & $1.66( \pm 1.47)$ & Mean (SD) & $1.72( \pm 0.83)$ \\
\hline Median & $1.20(1-10)$ & Median & $1.30(1-5)$ \\
\hline \multicolumn{2}{|l|}{ Initial Platelets } & \multicolumn{2}{|l|}{ Final Platelets } \\
\hline Mean (SD) & $264942.86( \pm 116262.432)$ & Mean (SD) & $276720.59( \pm 130449.835)$ \\
\hline Median & $236000.00(93000-592000)$ & Median & $255000.00(72000-630000)$ \\
\hline
\end{tabular}

ADEs, eight (88.9\%) needed enoxaparin prescription adjustment.

Among the 25 patients with enoxaparin overdose, 12 (48\%) had predictable ADEs related to enoxaparin use. Six patients presented bleeding, two hematuria, two petechiae, five hematomas (skin and mucous membranes) and 3 thrombocytopenia (haematological alterations - laboratory tests). The other thirteen overdose patients did not present enoxaparin-related ADE. Of the 44 patients prescribed the proper dose of enoxaparin, two presented bleeding, although neither of these patients were anticoagulated.

The major drug interactions with enoxaparin that result in increased anticoagulation were also analyzed in this study. A total of $63(90 \%)$ patients had at least one of these drugs prescribed concurrently with enoxaparin. The most frequent drug prescribed was metamizole $(88.6 \%)$, followed by warfarin $(31.4 \%)$, clopidogrel $(25.7 \%)$, fluoxetine $(11.4 \%)$, heparin $(7.1 \%)$ and venlafaxine (1.4\%). A comparison between the occurrence of ADE with and without the presence of these drugs is given in Table V.

It was found that $77.3 \%$ of the patients prescribed Warfarin concurrently with enoxaparin had ADE. Also, patients prescribed warfarin had a mean $35.4 \%$ INR increase, whilst patients without Warfarin had a mean INR increase of only $18.6 \%$. Furthermore, $87.5 \%$ of the patients prescribed Fluoxetine had ADE. Finally, 100\% of the patients who had ADE with correct prescription of enoxaparin and $90.5 \%$ of the patients who had ADE with unadjusted enoxaparin dosage were also given at least one drug known for interacting with enoxaparin and increasing the risk of bleeding. Although none of these results have statistical relevance, it is clinically valuable to investigate these adverse reactions.

\section{DISCUSSION}

The present study reports patients with stage CKD 3 to 5 requiring antithrombotic therapy, either for treatment of thromboembolic events or as prophylactic treatment, who were given enoxaparin as an antithrombotic drug in combination with other anticoagulant agents or not. It is known that enoxaparin bioaccumulates and causes bleeding if it is administered in therapeutic doses to patients with impaired renal function, especially in patients with creatinine clearance $<30 \mathrm{~mL} / \mathrm{min} / 1.73 \mathrm{~m}^{2}$ with unadjusted doses (Cadroy et al., 1991; Lim et al., 2006). Other factors that seem to increase the risk of bleeding in patients

TABLE V - Drug Interactions X ADE

\begin{tabular}{lcccccc}
\hline \multirow{2}{*}{ Results ( $=70)$} & & \multicolumn{2}{c}{ Drug interaction } & & \multicolumn{2}{c}{ No drug interaction } \\
\cline { 3 - 4 } \cline { 6 - 7 } & & ADE & No ADE & & ADE & No ADE \\
\hline Clopidogrel (\%) & $18(25.7)$ & $8(44.4)$ & $10(55.6)$ & & $35(67.3)$ & $17(32.7)$ \\
Fluoxetine (\%) & $8(11.4)$ & $7(87.5)$ & $1(12.5)$ & & $36(58.1)$ & $26(41.9)$ \\
Heparin (\%) & $5(7.1)$ & $1(20)$ & $4(80)$ & & $39(60)$ & $26(40)$ \\
Metamizole (\%) & $62(88.6)$ & $38(61.3)$ & $24(38.7)$ & & $5(62.5)$ & $3(37.5)$ \\
Warfarin (\%) & $22(31.4)$ & $17(77.3)$ & $5(22.7)$ & & $26(54.2)$ & $22(45.8)$ \\
Venlafaxine (\%) & $1(1.4)$ & $1(100)$ & 0 & & $42(60.9)$ & $27(39.1)$ \\
\hline
\end{tabular}


treated with enoxaparin include advanced age, obesity, low-weight and concomitant use of antiplatelet therapy. In this heterogeneous series of patients, enoxaparin was frequently prescribed inaccurately, as in the study by Devesa García et al. (2012), where enoxaparin was the drug most often (71\%) prescribed unadjusted. However, the present study data showed bleeding complications in all patients (with proper and unadjusted doses) and major bleeding in those with unadjusted doses.

Renal insufficiency is itself a risk factor for bleeding, as renal failure depresses erythropoiesis by decreasing erythropoietin production and promotes accumulation of toxins leading to bone marrow suppression (Gerlach et al., 2000). Regarding the use of enoxaparin in patients with GFR $<30 \mathrm{~mL} / \mathrm{min} / 1.73 \mathrm{~m}^{2}$, studies have shown higher plasma anti-factor Xa levels, along with higher incidence of major bleeding outcomes, in both DVT treatment or DVT prophylaxis enoxaparin doses. DeCarolis et al. (2012) reported an increased risk of major bleeding in patients with moderate renal impairment who received therapeutic doses of enoxaparin compared to healthy volunteers given the same drug. Chow et al. (2003) also found a linear relationship between GFR and anti-factor $\mathrm{X}$ a concentrations with enoxaparin. In contrast, TrujilloSantos et al. (2013) showed no difference in fatal bleeding between patients with GFR $>60 \mathrm{~mL} / \mathrm{min} / 1.73 \mathrm{~m}^{2}$ or $<30 \mathrm{~mL} / \mathrm{min} / 1.73 \mathrm{~m}^{2}$ and reported a two-fold mortality increase in the group receiving unfractionated heparin (UFH) versus those receiving any LMWH with GFR < $30 \mathrm{~mL} / \mathrm{min} / 1.73 \mathrm{~m}^{2}$.

The cited studies have shown the occurrence of bioaccumulation of enoxaparin in CKD patients. However, the presumed clinical relationship of increased bleeding with renal insufficiency for enoxaparin remains unclear. Sharif-Askari et al. (2014) compared patients with stages 3-5 CKD and noted a higher incidence of major bleeding with enoxaparin over UFH, although the risk of major bleeding was higher with UFH compared to enoxaparin. Thorevska et al. (2004) reported that unadjusted doses of both enoxaparin and UFH are associated with comparable increases in major bleeding complications in patients with renal dysfunction. Levine et al. (1989) showed a positive relationship between anti-factor Xa level and incidence of wound hematoma in hip replacement patients with oncedaily prophylactic enoxaparin, whereas Sanderink et al. (2002a) showed a significant increase in anti-factor Xa exposure in patients with severe renal impairment (GFR $<30 \mathrm{~mL} / \mathrm{min} / 1.73 \mathrm{~m}^{2}$ ) compared with healthy volunteers $(65 \%)$, demonstrating that dose adjustment in patients with severe renal impairment may be recommended. These results are consistent with the clinical findings of the present study, in which most ADEs and most severe ADEs identified in this study occurred in patients who required enoxaparin dose adjustment.

According to Pellizzari et al. (2018), a 150U/kg/day dose of enoxaparin for elderly patients with mild-tomoderate CKD (GFR $30-90 \mathrm{~mL} / \mathrm{min} / 1.73 \mathrm{~m}^{2}$ ) reduced the risk of overdosing and potentially the risk of bleeding, although they recommended anti-factor Xa assay in severe clinical situations that require higher anticoagulant activity. Conversely, Pannuci et al. (2017) showed that alterations in enoxaparin dose level based on patient weight prevent a high proportion of patients from achieving appropriate anti-factor Xa levels when oncedaily enoxaparin prophylaxis is provided.

Studies have shown that patients with excessive body weight may not be adequately treated with fixeddose enoxaparin thromboprophylaxis, while patients with lower body weight may have an increased bleeding risk. Celik et al. (2015) found a strong negative correlation between body weight and peak anti-Xa levels, as 38\% of patients with excessive body weight $(>150 \mathrm{~kg})$ had subprophylactic anti-Xa levels with fixed-dose enoxaparin. Similarly, anti-factor Xa activity rises significantly when body weight decreases. In the study performed by Rojas et al. (2013), low-weight patients, especially those weighing $>45 \mathrm{~kg}$, exhibited an antifactor Xa activity higher than the desired range for thromboembolic prophylaxis.

In a small pharmacodynamic study, Sanderink et al. (2002b) compared anti-factor Xa concentrations in obese and non-obese patients. The authors observed that enoxaparin was well tolerated in both obese and non-obese volunteers. Therefore, they concluded that it does not appear necessary to modify the current dose recommendation of enoxaparin $(1.5 \mathrm{mg} / \mathrm{kg}$ administered once daily) when treating obese volunteers. Spinler et al. (2003) analyzed both Efficacy Safety Subcutaneous Enoxaparin in Non-Q-wave Coronary Events (ESSENCE) and Thrombolysis in Myocardial Infarction (TIMI) 11B studies regarding safety and efficacy of UFH and enoxaparin in patients who are obese and patients with severe renal impairment. They concluded that obesity did not impact clinical outcomes, whereas patients with severe renal impairment have a higher risk of clinical events and major and any hemorrhages than patients without severe renal impairment, whether they are treated with UFH or enoxaparin. This suggests that bleeding complications are not associated with enoxaparin but with renal insufficiency itself, for not only enoxaparin dose is involved with the occurrence of ADE in severe CKD patients. 
Ambiguity surrounding drug interactions may lead to variations in practice. Furthermore, the lack of clinical studies to support each specific agent precludes the correlation of pharmacokinetic changes with outcomes. In the study performed by Samuel, Seifert (2017) no difference was found in the incidence of major bleeding in patients on LMWH and SSRIs versus those on LMWH but not on SSRIs. Castro, Heineck (2012) analyzed the contribution of drug interactions to INR results outside the therapeutic range in patients anticoagulated with warfarin. They concluded that the drug characteristics have a greater influence on the test results than does the number of drugs. In the present study, many drug interactions were observed, although the correlation between them and the related outcomes remains unclear, as the presence of drug interactions was not determined for the occurrence of ADE (many patients with drug interactions had no ADE). However, the study results also indicate that the concurrent use of enoxaparin with the aforementioned drugs (especially warfarin, which was involved with most INR increases) should be monitored, as almost all patients who presented ADE had at least one of these drugs prescribed along with enoxaparin.

Finally, studies on prescriptions for patients with CKD demonstrate abundant opportunities for pharmaceutical interventions. Arrabal-Durán et al. (2014) described that the percentage of drug interventions in comparison with the total number of drugs that were reviewed is high and the most frequent type of adjustment observed was dose reduction, which is consistent with the results of the present study. In fact, Barras et al. (2010) demonstrated that individualized dosing in subjects with renal impairment (properly adjusted doses) is more effective than conventional dosing at achieving and maintaining therapeutic anticoagulation, which could decrease the risk of bleeding events and mortality in these patients. Therefore, the role of clinical pharmacists in the management of CKD patients is crucial, as dose adjustments are often necessary and determine outcomes which can be life-saving or life-threatening.

\section{Limitations}

Within the hospital where the study was carried out, there is no standard institutional protocol for dose adjustment according to renal function and therefore each prescriber has autonomy to perform dose adjustment. Owing to the lack of a consensus on exact dosage and dosage according to GFR, the pharmacy service, based on research of reliable sources, has set standards for some selected medications. From this standardization, it was possible to establish and classify the necessary prescription adjustments. Given there are several sources of research, there may be differences in the patterns for dose adjustment considered in the present study when compared to other investigations.

Since enoxaparin does not affect activated clotting time or activated partial thromboplastin time, laboratory monitoring may be performed by measuring anti-factor Xa levels. Unfortunately, no patients in this study had their anti-factor Xa levels tracked due to the lack of standard institutional protocol for this monitoring. However, although anti-factor $\mathrm{Xa}$ is currently considered the gold standard when LMWH monitoring is required, it is an indirect measure of the amount of LMWH in plasma and does not directly measure the anticoagulant effect. Thus, alternative techniques for direct measurement of the anticoagulant effect of LMWH are required.

Metamizole was often prescribed in an "if necessary" condition. Despite being prescribed for a large number of patients with $\mathrm{ADE}$, it was not possible to fully explore the relationship between the drug and ADE; there is uncertainty as to the effective use of the drug.

Finally, a limitation of this study is the small sample size. Although none of the results have statistical relevance, it is clinically valuable to investigate these adverse reactions.

\section{CONCLUSION}

Anticoagulation therapy in hospitalized patients with CKD is significantly associated with an increased risk of major bleeding and in-hospital mortality. The results of this study suggest an overall increased risk of major bleeding and ADEs in patients who require enoxaparin prescription adjustment. Further investigation of alternative dosing regimens in patients with CKD to maintain efficacy while reducing risks is imperative, as are studies on the utility of monitoring anti-factor Xa activity to guide dosing of enoxaparin. In addition, the role of clinical pharmacists in the management of CKD patients is crucial, as dose adjustments are often necessary.

\section{REFERENCES}

Aronoff GR BW, Berns JS, Brier ME, Kasbekar N, Mueller BA, Pasko DA, Smoyer WE. Drug prescribing in renal failure: dosing guidelines for adults, Fifth Edition; Versa Press; 2007.

Arrabal-Durán P, Durán-García ME, Ribed-Sánchez A, HidalgoCollazos P, Sanjurjo-Sáez M. Pharmaceutical interventions in prescriptions for patients admitted with chronic renal failure. Nefrologia. 2014;34(6):710-5. 
Barras MA, Duffull SB, Atherton JJ, Green B. Individualized dosing of enoxaparin for subjects with renal impairment is superior to conventional dosing at achieving therapeutic concentrations. Ther Drug Monit. 2010;32(4):482-8.

British Medical Association, Royal Pharmaceutical Society of Great Britain. British National Formulary. London: BMA, RPS, ( $\mathrm{N}^{\mathrm{o}}$ 64); 2012.

Brophy DF, Wazny LD, Gehr TW, Comstock TJ, Venitz J. The pharmacokinetics of subcutaneous enoxaparin in end-stage renal disease. Pharmacotherapy. 2001;21(2):169-74.

Cadroy Y, Pourrat J, Baladre MF, Saivin S, Houin G, Montastruc $\mathrm{JL}$, Vernier I, et al. Delayed elimination of enoxaparin in patients with chronic renal insufficiency. Thromb Res. 1991;63(3):38590 .

Castro TA, Heineck I. Interventions to improve anticoagulation with warfarin. Ther Drug Monit. 2012;34(2):209-16.

Celik F, Huitema AD, Hooijberg JH, van de Laar AW, Brandjes DP, Gerdes VE. Fixed-dose enoxaparin after bariatric surgery: the influence of body weight on peak anti-Xa levels. Obes Surg. 2015;25(4):628-34.

Chow SL, Zammit K, West K, Dannenhoffer M, LopezCandales A. Correlation of antifactor Xa concentrations with renal function in patients on enoxaparin. J Clin Pharmacol. 2003;43(6):586-90.

Coresh J, Selvin E, Stevens LA, Manzi J, Kusek JW, Eggers $\mathrm{P}$, et al. Prevalence of chronic kidney disease in the United States. JAMA. 2007;298:2038-2047.

Dager WE, Kiser TH. Systemic anticoagulation considerations in chronic kidney disease. Adv Chronic Kidney Dis. 2010;17(5):420-7.

de Jong PE, Gansevoort RT. Fact or fiction of the epidemic of chronic kidney disease--let us not squabble about estimated GFR only, but also focus on albuminuria. Nephrol Dial Transplant. 2008;23(4):1092-5.

DeCarolis DD, Thorson JG, Clairmont MA, Leuthner AM, Rector TS, Johnson GJ. Enoxaparin outcomes in patients with moderate renal impairment. Arch Intern Med. 2012;172(22):1713-8.
Devesa García C, Matoses Chirivella C, Peral Ballester L, Sanz Tamargo G, Murcia López AC, Navarro Ruiz A. Atención farmacéutica en pacientes ingresados con insuficiencia renal. Farm Hosp. 2012;36(6):483-91.

Gerlach AT, Pickworth KK, Seth SK, Tanna SB, Barnes JF. Enoxaparin and bleeding complications: a review in patients with and without renal insufficiency. Pharmacotherapy. 2000;20(7):771-5.

Jalal DI, Chonchol M, Targher G. Disorders of hemostasis associated with chronic kidney disease. Semin Thromb Hemost. 2010;36(1):34-40.

Levey AS, Atkins R, Coresh J, Cohen EP, Collins AJ, Eckardt $\mathrm{KU}$, et al. Chronic kidney disease as a global public health problem: approaches and initiatives - a position statement from Kidney Disease Improving Global Outcomes. Kidney Int. 2007;72(3):247-59.

Levine MN, Planes A, Hirsh J, Goodyear M, Vochelle N, Gent M. The relationship between anti-factor Xa level and clinical outcome in patients receiving enoxaparine low molecular weight heparin to prevent deep vein thrombosis after hip replacement. Thromb Haemost. 1989;62(3):940-4.

Lim W, Dentali F, Eikelboom JW, Crowther MA. Meta-analysis: low-molecular-weight heparin and bleeding in patients with severe renal insufficiency. Ann Intern Med. 2006;144(9):673-84.

MEDSCAPE (Internet). Copyright (C) 1994-2014. [citad 2018 Feb 11] Available from: http//reference.medscape.com/ pharmacists.

Micromedex. DRUG-REAX ${ }^{\circledR}$ System (Electronic Version); Truven Health Analytics: Greenwood Village, C., USA; 2014. [citad 2018 Feb 11] Available from: http://wwwmicromedexsolutionscom.ez27.periodicos.capes.gov.br

Pannucci CJ, Hunt MM, Fleming KI, Prazak AM. Weight-based dosing for once-daily enoxaparin cannot provide adequate anticoagulation for venous thromboembolism prophylaxis. Plast Reconstr Surg. 2017;140(4):815-822.

Pellizzari L, Facchinetti R, Corrà L, Sepe A, Fantin F, Fontana $\mathrm{G}$, et al. Can we reliably predict the level of anticoagulation after enoxaparin injection in elderly patients with renal failure? Aging Clin Exp Res. 2018;30(6):605-608. 
Product Information: Lovenox ${ }^{\circledR}$ subcutaneous injection, intravenous injection, enoxaparin sodium subcutaneous injection, intravenous injection. Sanofi-Aventis US LLC (per FDA), Bridgewater, NJ; 2017.

Rojas L, Aizman A, Ernst D, Acuña MP, Moya P, Mellado $\mathrm{R}$, Cerda J. Anti-Xa activity after enoxaparin prophylaxis in hospitalized patients weighing less than fifty-five kilograms. Thromb Res. 2013;132(6):761-4.

Rondina MT, Wheeler M, Rodgers GM, Draper L, Pendleton RC. Weight-based dosing of enoxaparin for VTE prophylaxis in morbidly obese, medically-ill patients. Thromb Res. 2010;125(3):220-3.

Samuel NG, Seifert CF. Risk of bleeding in patients on full-dose enoxaparin with venous thromboembolism and selective serotonin reuptake inhibitors. Ann Pharmacother. 2017;51(3):226-231.

Sanderink GJ, Guimart CG, Ozoux ML, Jariwala NU, Shukla UA, Boutouyrie BX. Pharmacokinetics and pharmacodynamics of the prophylactic dose of enoxaparin once daily over 4 days in patients with renal impairment. Thromb Res. 2002a;105(3):22531 .

Sanderink GJ, Le Liboux A, Jariwala N, Harding N, Ozoux ML, Shukla U, et al. The pharmacokinetics and pharmacodynamics of enoxaparin in obese volunteers. Clin Pharmacol Ther. 2002b;72(3):308-18.

Shaikh SA, Regal RE. Dosing of enoxaparin in renal impairment. P T. 2017;42(4):245-249.

Sharif-Askari SF, Syed Sulaiman SA, Sharif-Askari SN, Al Sayed Hussain A, Railey MJ. Adverse outcomes of anticoagulant use among hospitalized patients with chronic kidney disease: a comparison of the rates of major bleeding events between unfractionated heparin and enoxaparin. PLoS One. 2014;9(9):e106517.

Sherman DG, Albers GW, Bladin C, Fieschi C, Gabbai AA, Kase CS, et al. The efficacy and safety of enoxaparin versus unfractionated heparin for the prevention of venous thromboembolism after acute ischaemic stroke (PREVAIL Study): an open-label randomised comparison. Lancet. 2007;369(9570):1347-55.
Spinler SA, Inverso SM, Cohen M, Goodman SG, Stringer KA, Antman EM, et al. Safety and efficacy of unfractionated heparin versus enoxaparin in patients who are obese and patients with severe renal impairment: analysis from the ESSENCE and TIMI 11B studies. Am Heart J. 2003;146(1):33-41.

Thorevska N, Amoateng-Adjepong Y, Sabahi R, Schiopescu I, Salloum A, Muralidharan V, et al. Anticoagulation in hospitalized patients with renal insufficiency: a comparison of bleeding rates with unfractionated heparin vs enoxaparin. Chest. 2004;125(3):856-63.

Trujillo-Santos J, Schellong S, Falga C, Zorrilla V, Gallego P, Barrón M, Monreal M; RIETE Investigators. Low-molecularweight or unfractionated heparin in venous thromboembolism: the influence of renal function. Am J Med. 2013;126(5):425-434.

UpToDate. [citad 2018 Feb 11] Available from: http://www. UpToDate.com/home/inde x.htmL.

Verbeeck R, Musuamba F. Pharmacokinetics and dosage adjustment in patients with renal dysfunction. Eur J Clin Pharmacol. 2009;65(8):757-73.

Via-Sosa MA, Lopes N, March M. Effectiveness of a drug dosing service provided by community pharmacists in polymedicated elderly patients with renal impairment--a comparative study. BMC Fam Pract. 2013;14:96.

World Health Organization (WHO). The importance of pharmacovigilance: Safety monitoring of medicinal products. Geneva; 2002.

Yeung CK, Shen DD, Thummel KE, Himmelfarb J. Effects of chronic kidney disease and uremia on hepatic drug metabolism and transport. Kidney Int. 2014;85(3):522-8.

Received for publication on $21^{\text {st }}$ April 2018 Accepted for publication on $21^{\text {st }}$ June 2018 